\title{
Analysis of Distance Learning in the Professional School of Systems Engineering and Informatics
}

\author{
Eleazar Flores Medina ${ }^{1}$ \\ Departamento de Estudios Generales \\ Universidad de Ciencias y Humanidades \\ Lima, Perú
}

\author{
Janet Corzo Zavaleta ${ }^{4}$ \\ Departamento de Estudios Generales \\ Universidad de Ciencias y Humanidades \\ Lima, Perú
}

\author{
Yrma Principe Somoza ${ }^{2}$ \\ Departamento de Estudios Generales \\ Universidad de Ciencias y Humanidades \\ Lima, Perú
}

\author{
Roberto Yon Alva ${ }^{5}$ \\ Departamento de Estudios Generales \\ Universidad de Ciencias y Humanidades \\ Lima, Perú
}

\author{
Laberiano Andrade-Arenas ${ }^{3}$ \\ Facultad de Ciencias e Ingeniería \\ Universidad de Ciencias y Humanidades \\ Lima, Perú
}

\begin{abstract}
Samuel Vargas Vargas ${ }^{6}$
Departamento de Estudios Generales

Universidad de Ciencias y Humanidades

Lima, Perú
\end{abstract}

\begin{abstract}
The distance modality exponentially accelerated the use of technological tools in times of pandemic. In this context, educational institutions at all levels implemented actions to strengthen teaching work through training. The present study was carried out in the University of Sciences and Humanities considering the distance teaching process that is based on three dimensions: teaching strategy, resources and pedagogical materials, and evaluation. The study objective to analyze the distance learning process in its 3 dimensions to propose solutions in virtual teaching. The applied methodology was of a mixed approach; that is, qualitative through focus group and quantitative through student survey. The student population of 159 and a sample of 113 with a confidence level of $95 \%$ and margin of error $5 \%$.The result obtained in the focus group shows that teachers have difficulties in the application of teaching strategies in the virtual modality evidenced in the management of digital tools, elaboration of rubrics to evaluate learning, and in the use of resources and pedagogical materials. This is complemented with surveys that show partial acceptance of teaching work in the distance modality; that is, the teaching strategy has an average of 3,76 and standard deviation (S.D) ,63 and $58,41 \%$ agrees with the teacher's teaching strategy; likewise, the pedagogical resources and materials dimension was obtained an average of 3,72 and S.D ,74 and agrees $51,33 \%$.Also in the evaluation, an average of 3,76 and S.D ,72 were obtained with a 55,75\% according to the way the teacher evaluates. The research work serves as input for future curricular designs in the distance modality.
\end{abstract}

Keywords-Distance modality; evaluation; focus group; resources and pedagogical materials; teaching strategy

\section{INTRODUCTION}

Distance education requires, in addition to resources, the preparation of teaching and administrative staff, accessibility and motivation of students for integrated learning based on ICT [1]. In Peru the access to internet has been steadily increasing these last years [2]. In March 2020, the first case of COVID-19 was detected in Peru, which led the central government to take economic and political measures that impacted on the Peruvian education, one of these being the suspension of classes at all levels [3]. Likewise, the Ministry of Education (MINEDU) established measures for distance education; so universities, professors and students had to adapt to the new context [4].
Later, the University of Sciences and Humanities (UCH) implemented the distance modality as an emergency measure. In this context, it was evidenced that although the teaching staff had experience and acceptance in the face-to-face modality, they lacked the management of methodologies and strategies at a virtual level [5]. Teachers had difficulty applying teaching strategies, using resources and pedagogical materials, as well as evaluating their students' learning. For this reason, trainings were carried out with teachers before classes began and during the semester [6].

The trainings focused on the use of digital tools, such as digital whiteboards, technological resources, among others; thus also in the proper use of the MOODLE platform where teachers upload their pedagogical resources and materials; furthermore, at the university, teachers and students use Zoom videoconferencing to interact in the teaching and learning process [7]. Faced with the COVID-19 pandemic, institutions have opted for virtual learning through the MOOC model that focuses on the student (LCM) and the MOODLE learning system. To increase the effectiveness of this process, a feedback and evaluation system has been incorporated. Also, a series of structures such as dialogues, videos, activities, learning experience interactions and questionnaires.

From the problem presented, the following question is formulated. What is the perception of the students, about the teaching process, in the distance modality of the Professional School of Systems Engineering and Informatics?

The objective of this research is to analyze the perception of students about the teaching process in the distance modality, taking into consideration the teaching strategy, the pedagogical resources and materials and the evaluation, of the Professional School of Systems Engineering and Informatics, through the focus group and surveys with the students. This in order to contribute to the continuous improvement and educational quality of the university.In this sense, this research work is relevant because it allows approaching teaching work in the distance modality and contributing to the university community, since it is specifically directed to the academic aspect. It also seeks to propose new actions that enhance the teaching process and the application of strategies in the distance modality 
The article presents the following structure: Section I, the introduction, Section II presents the review of the Literature, where the background is explained; In Section III, the methodology is exposed, detailing the steps to follow in each stage of the process; then Section IV indicates the results obtained, in Section V discussions, and finally, we have Section VI with conclusions and future work.

\section{LiteratURE REVIEW}

In his research work, analyzes the consequences of moving from classroom teaching to distance learning during the COVID-19 pandemic; where it emphasizes that the teaching strategy and the evaluation system are different in these modalities [8]. It also presents the contingency plans that were put in place so that teaching is not affected. At the same time, he emphasized the strategies to reduce student desertion, among which stands out, having teachers who adapt to the distance modality; For this reason, trainings were developed for teachers in technological resources, virtual teaching strategy, among others.

In his article, he conducted a survey of students who point out that distance education has positive and negative aspects; likewise, teachers must be trained in the teaching process and in the use of educational platforms to face this new modality [9].

In his study on education in times of pandemic points out that teachers must enhance their technological and pedagogical knowledge [10]. To do this, surveys were conducted with students and teachers, reaching the conclusion that teachers have to be able to innovate, reflect and transform their didactic proposals in order to provide quality education.

The importance of the use of technological resources by teachers, so that they can interact with their students in the teaching process [11]. In the conclusions obtained, they highlighted that teachers must be trained in the use of educational platforms and digital tools to reduce dissatisfaction on the part of students in distance learning.

In addition, a study carried out on the perception of students, in relation to learning in the distance and face-toface modality, was carried out by [12], with students from the University of Indonesia. The results show that students have a greater perception of face-to-face learning compared to virtual learning. Among the aspects that stand out we have: presence and social interaction and satisfaction. Despite the results, the difference between both learning modalities is not significant, since some students indicated that they felt comfortable learning in the distance modality, because it allowed them to innovate through technology.

The study carried out by [13], examines the attitudes of Portuguese university students in the remote mode during the COVID-19 pandemic. The surveyed students agree with the teaching and evaluation methodologies in this new modality; however, they feel the need for face-to-face classes for practical and laboratory classes.

On the other hand, the study carried out by [14], aimed to capture the teaching experiences in the process of transition to virtual education in its early stages. To this end, a questionnaire was distributed to six groups of Swedish teachers through Facebook groups on preparing teachers and schools for distance education. The results indicate that there are four fundamental pedagogical activities for this teaching modality: teacher and school preparation, strategies for distance education, pedagogical activities, and positive experiences and challenges. It is concluded that distance education leads to a rapid change that can become more complex; For this reason, it is necessary to use technological tools, that is, to focus on the available devices and applications, but the teachers lacked previous experience; Likewise, activities such as communication, collaboration, exchange of learning materials, workload, evaluation and exams were emphasized.

\section{Methodology}

The research was carried out at the University of Sciences and Humanities in Lima, Peru and this presents a qualitativequantitative approach, of an exploratory-descriptive scope, not experimental.Teaching at the university under study was synchronous. The study variable is teaching with the 3 dimensions (D) shown in Fig. 1. The dimensions come to disaggregate the teaching variable.

\section{A. Focus Group to Students}

The focus group was carried out virtually (evidence in Fig. 2) and had the participation of nine students from the fifth to the tenth semester of the Professional School of Systems and Informatics, where the recording of the focus group and the evidence of the photo It was with the consent of the students and respecting the code of ethics of the university. The purpose of the focus group was to collect information on the perception of students in relation to teaching, from the dimensions of Fig. 1. The interview was structured, for which an eight question guide was prepared, validated by experts in the field. In Fig. 3 , the processes that were carried out in the focus group are shown:

- Start: Those involved were identified: students, researchers and the moderator of the interview. The selected students were nine.

- Planning: The requirements for the focus group were compiled and the activities and tasks to be carried out on scheduled dates were defined.

- Execution: The implementation of the focus group was directed to guarantee and ensure the event.

- Closing: The recording and writing of the report of the Focus group was carried out.

\section{B. Student Surveys}

TABLE I. EXPERT JUDGMENT

\begin{tabular}{|c|c|c|c|c|}
\hline Question & Expert1 & Expert2 & Expert3 & Percent \\
\hline 1 & $80 \%$ & $85 \%$ & $90 \%$ & $85 \%$ \\
\hline 2 & $75 \%$ & $80 \%$ & $85 \%$ & $80 \%$ \\
\hline 3 & $70 \%$ & $90 \%$ & $80 \%$ & $80 \%$ \\
\hline 4 & $90 \%$ & $90 \%$ & $90 \%$ & $90 \%$ \\
\hline 5 & $80 \%$ & $80 \%$ & $80 \%$ & $80 \%$ \\
\hline 6 & $90 \%$ & $90 \%$ & $90 \%$ & $90 \%$ \\
\hline 7 & $70 \%$ & $90 \%$ & $80 \%$ & $80 \%$ \\
\hline 8 & $90 \%$ & $90 \%$ & $90 \%$ & $90 \%$ \\
\hline
\end{tabular}




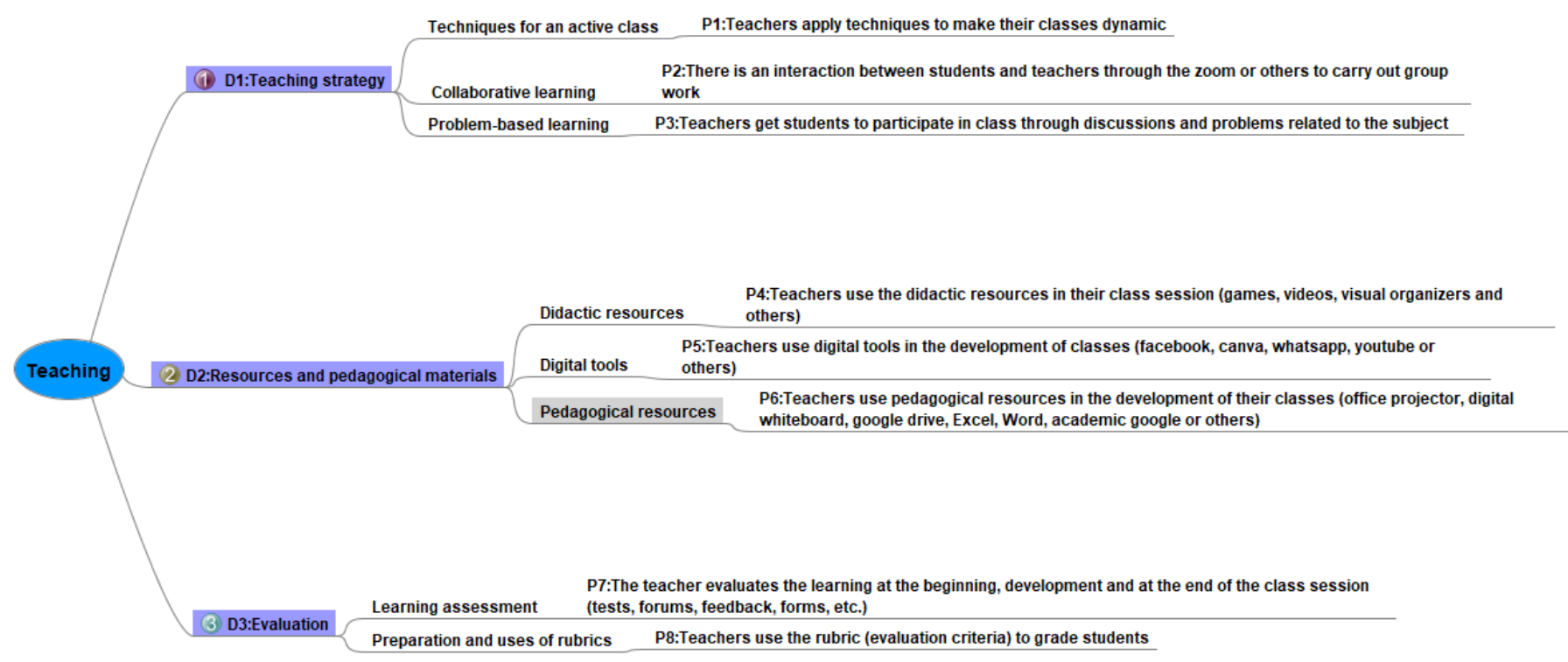

Fig. 1. Teaching Dimensions.

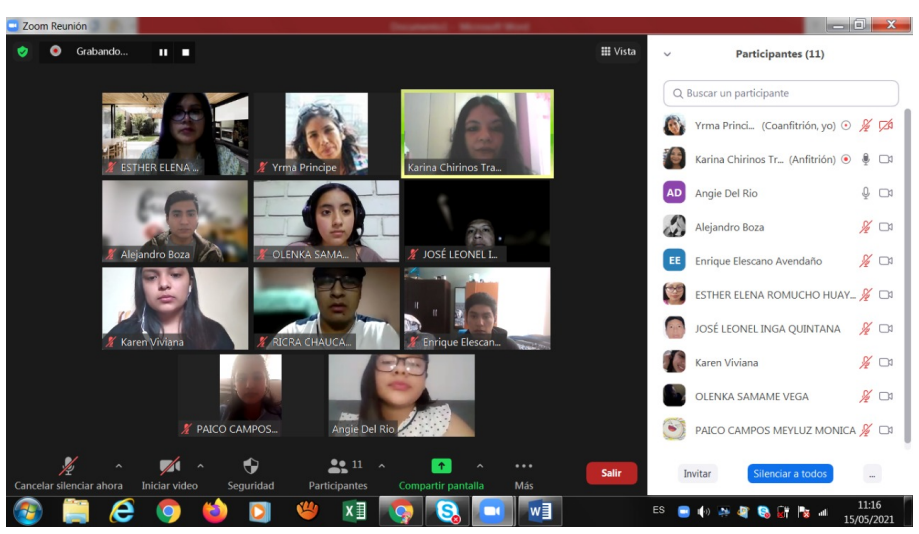

Fig. 2. Focus Group to Students.

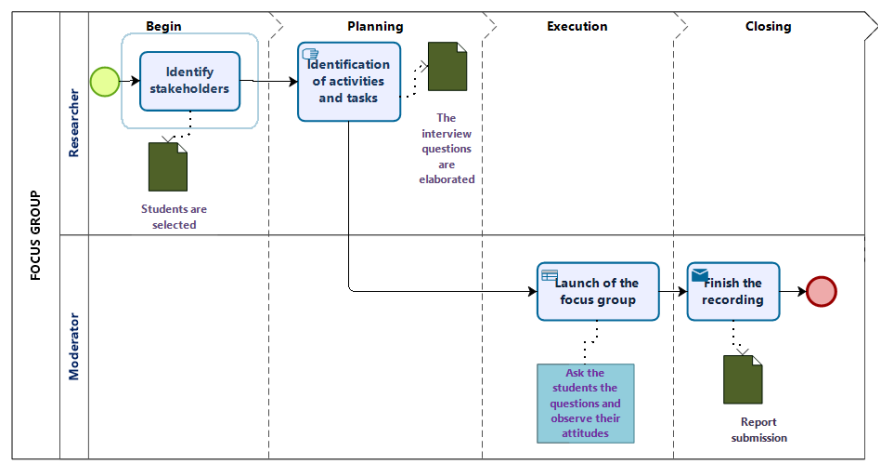

Fig. 3. Focus Group Process.
The student population of the Professional School of Systems and Informatics consists of a total of 159 students. Simple random sampling was applied, obtaining as a sample (N) 113 students, with a confidence level of $95 \%$ and margin of error of $5 \%$. The survey link is: https://n9.cl/7at2k

The first three questions focus on the first dimension: teaching strategy; From the fourth question to the sixth, the second dimension was applied, which is pedagogical resources and materials, and the seventh and eighth questions cover the evaluation dimension. Likewise, the Likert scale from 1 to 5 was applied, with 1 strongly disagreeing, 2 disagreeing, 3 moderately agreeing, 4 agreeing, 5 strongly agreeing.

The content of the instrument was validated by expert judgment, as shown in Table I, based on the following criteria:

- Drafting: The questions are clear and precise.

- Relevance: The questions asked are appropriate and timely.

- Coherence: There is a logical coherence between the dimensions and the questions asked.

- Understanding: There is a comprehensive understanding of all questions.

To carry out the assessment, each criterion was sought to have an interval of 25 points (one point equals $1 \%$ ) For example: expert 1 placed 20 points on the first question to write $(20 \%)$, relevance $25 \%$ consistency $25 \%$ y understanding $10 \%$; where the sum of them is $80 \%$. Then in Table I it is placed $80 \%$ and so on until the entire table is filled with the 
scores that the other experts placed. After filling in the table, the average of the last column is taken, obtaining as a result $84,375 \%$. The general average must be greater than $75 \%$ To give the content as Validated, therefore, it can be noted that the instrument has been validated by expert judgment.

A pilot test was carried out with 16 students representing $10 \%$ o of the sample where no observations were found. Likewise, the reliability and internal consistency test and validation of the instrument shown in Table II were carried out, obtaining Cronbach's Alpha 0,921, which shows high reliability, since its value is close to 1 ; on the other hand, the validation was obtained using Factorial Analysis with the Kaiser Meyer and Olkin (KMO) index, obtaining 0,753, thus demonstrating that the scale is valid because it is greater than 0.5; likewise, in Bartlett, 0.000 was obtained, being less than 0,05 . Therefore, the instrument is reliable and validated; all this was done using the SPSS statistics 23 software.

TABLE II. RELIABILITY AND VALIDATION OF THE INSTRUMENTS

\begin{tabular}{lll}
\hline Cronbach's Alpha & KMO & Bartlett \\
\hline \hline Reliability & Validation & Validation \\
\hline It must be greater & It must be greater & It must be p less \\
than or equal to 0,7 & than or equal to 0,5 & than 0,05 \\
\hline 0,921 & 0,753 & 0,000 \\
\hline
\end{tabular}

\section{RESUlts}

\section{A. Analysis of the Data on the Focus Group}

After the Focus Group recording, the video was observed on several occasions. Likewise, the audio was transcribed and then the most significant responses of the students were underlined. Subsequently, the questions in rows and the refined answers in columns were placed in a matrix.

In Fig. 4, the procedure for the analysis of the Focus Group data is shown, through a flow chart, from the beginning, which is the collection of data obtained from the recording, until the closing, which is the writing after having passed for validation.

-Analysis by dimensions

1) Teaching strategy: In this dimension, three questions were asked.

Question 1. Do you think that your teachers apply techniques so that their classes are active?

The students stated that the teachers partially use the techniques to make their classes active. The sections and techniques that are carried out in distance classes must be supported by tools to fulfill the objective of being more dynamic teaching. However, they observe that teachers do not use these tools adequately to motivate students and thus be dynamic in their classes. According to the author [15], in his research, classes become dynamic when they use digital tools appropriately; so it is necessary to train in its use; that is, university teachers should have more training so that their classes are more active and motivating using digital tools as a complement.

Question 2. Is interaction between students observed in group work carried out by the teacher to improve their learning?

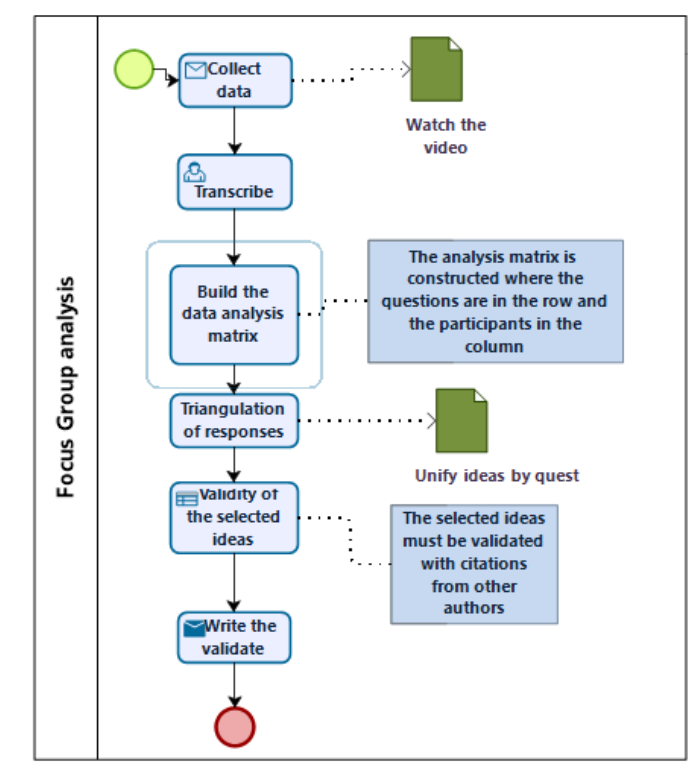

Fig. 4. Focus Group Procedure.

Students point out that interaction in group or collaborative work is not what is expected. But if there are teachers who use collaborative tools through Zoom, they have the option to form groups with students and also chat; since, through these means, teachers and students interact. According to the author [16], is important that teachers know how to handle the Zoom videoconference, such as the group room, so that their students can carry out their work in class where the teacher plays the role of mediator.

Question 3. Do you think that teachers make students be participative and not passive in the development of the class?

According to the students, most of the teachers, at the beginning, dictated as they did in the face-to-face modality, but as they were trained they improved in the teaching process and this made their students more participatory in the forums of debates, in class sessions. Likewise, the majority of students use mobile phones more than computers, which means that teachers must develop strategies to promote the participation of students from their cell phones. The author [17], in his study indicates that the teacher must apply strategies so that the students are more participative in the distance mode, based on the use of virtual tools, since the students use various devices, mainly mobile phones.

2) Resources and pedagogical materials: In this dimension, three questions were asked.

Question 4. How do teachers use the teaching resources in their class session?

Students responded that teachers use visual and audiovisual teaching resources such as videos, some virtual tools and the Internet. The difficulty they present is that most of the students use mobile phones and that is a limitation due to the little data and time that they can use it for a class of several hours; as well as, they have internet connectivity and stability problems. According to the author of the article, distance learning allows interaction from any space between the teacher and students, as 
well as between students; however, it is a complication for the teacher of not having all the hardware and software accesses to carry out a session of appropriate class using teaching resources.

Question 5. What is your opinion about the use of digital tools in the development of the class?

WhatsApp is the digital communication tool most frequently used by teachers and students. They create groups for classrooms and communicate to carry out tasks, tests to be carried out and notices. Therefore, what must be done is to bear in mind the rules of coexistence from the beginning on the use of this tool. Online applications and tools in teaching [18] they are fundamental, since the students partially use the computer, and rather use mobile phones as their main means, and communications are generally carried out through WhatsApp.

Question 6. How do teachers use pedagogical resources in the development of their classes?

Teachers use pedagogical resources with limitations, but the materials are shared in the Moodle platform or virtual classroom and these are used in synchronous classes. Likewise, teachers use a digital blackboard, teach their students the use of Google drive so that they can organize their information; students also use information search engines. As for the tools that the teacher has on the Moodle platform, these are used during class, but they are not fully explored. The author [19], points out that the students' perception of the use of technological resources is that it served as support in their learning process and facilitated progress in the organization of their knowledge.

3) Evaluation: In this dimension, two questions were asked.

Question 7. Do you think that the teacher evaluates at the beginning, development and at the end of his class session?

In classes, few teachers evaluate at the beginning of the process and at the end of the class. Generally, they carry out their classes according to the syllable; and some teachers evaluate through the Moodle platform; while others use technological tools such as Mentimeter and Quizizz. The author analyzes the use of LMS (learning management system),for example Moodle,which is the platform used by the university under study, pointing out that on this platform evaluations can be carried out through questionnaires and other tools that the platform offers, carried out by their teachers after having been trained in the use of it.

Question 8. Do you think that teachers use the rubric criteria appropriately in their evaluation?

For students, some teachers apply rubrics, but the vast majority do not. Likewise, the teachers who use the rubrics in their evaluation system in the exams, graded practices or others do so in an inappropriate way, since they do not present them to the students, nor do they explain them; Therefore, the students do not know the criteria by which they will be evaluated. The author [20], in his research, analyzes the use of rubrics and their scores according to each criterion established in the evaluation and disseminates this with his students as they will be evaluated. In summary, the students point out the need to train teachers in the management and elaboration of rubrics.

\section{B. About Student Survey}

1) Analysis of the dimensions: In the dimension of teaching strategy, $58,41 \%$ points out that teachers apply strategies with a mean of 3,76 and S.D ,63 (see Fig. 5), however, a 17,70\% moderately agrees on the use of the teaching strategy.

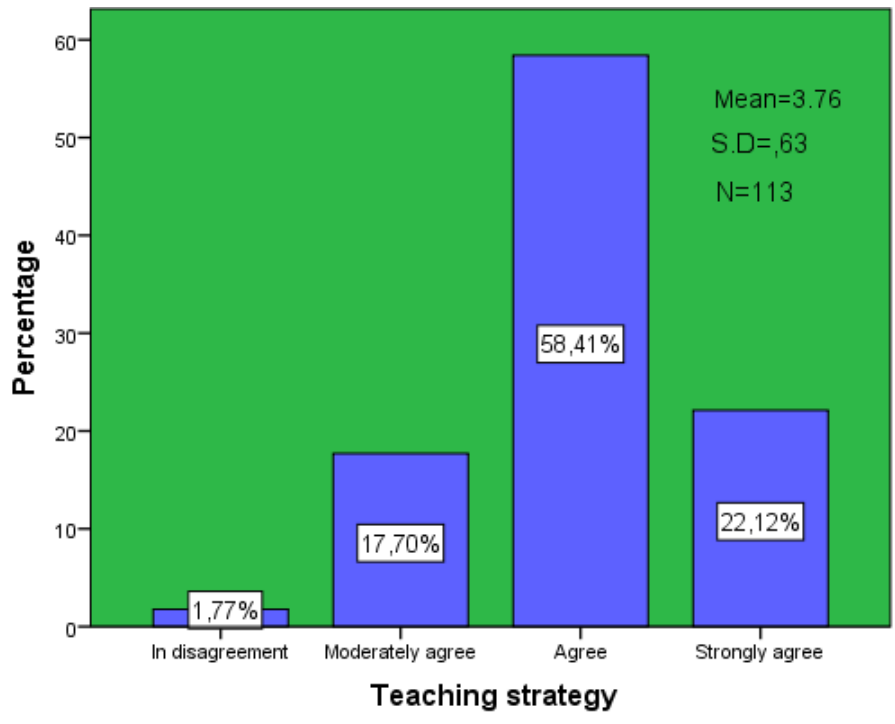

Fig. 5. Dimension 1: Teaching Strategy.

Also, in Fig. 6, the 51,33\% agrees on the use of pedagogical resources and materials, that is, teachers upload their materials to the virtual classroom and $18,58 \%$, moderately agree. This dimension has a mean of 3,72 with a standard deviation of, 74 which indicates that it is slightly above normal. El 55,75\%

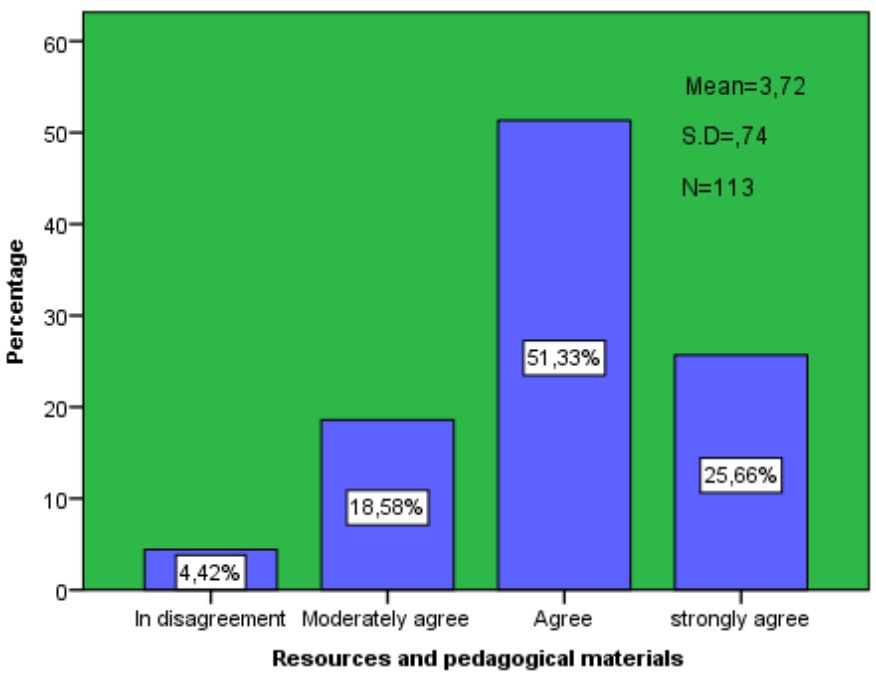

Fig. 6. Dimension 2: Resources and Pedagogical Materials.

agree that teachers partially use evaluation at the entrance, process and exit of a class session. There is also $19.47 \%$ that moderately agrees, see (Fig. 7). 


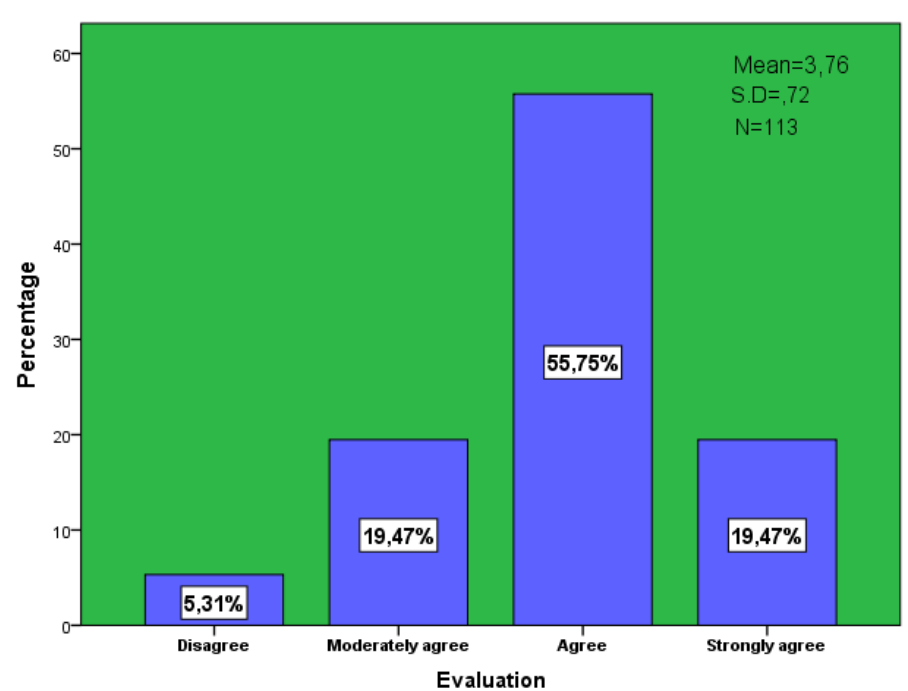

Fig. 7. Dimension 3: Evaluation.

2) Analysis by questions: Each question that was placed as affirmations is analyzed (See Fig.1).

P1: Teachers apply techniques to make their classes dynamic

In the question about the techniques for active and dynamic classes, an average of 3,72 was obtained and S.D of, 761. That is, the teachers have partial acceptance; in addition, $28,32 \%$ moderately agree, (see Fig. 8).

Teachers apply techniques to make their classes dynamic?

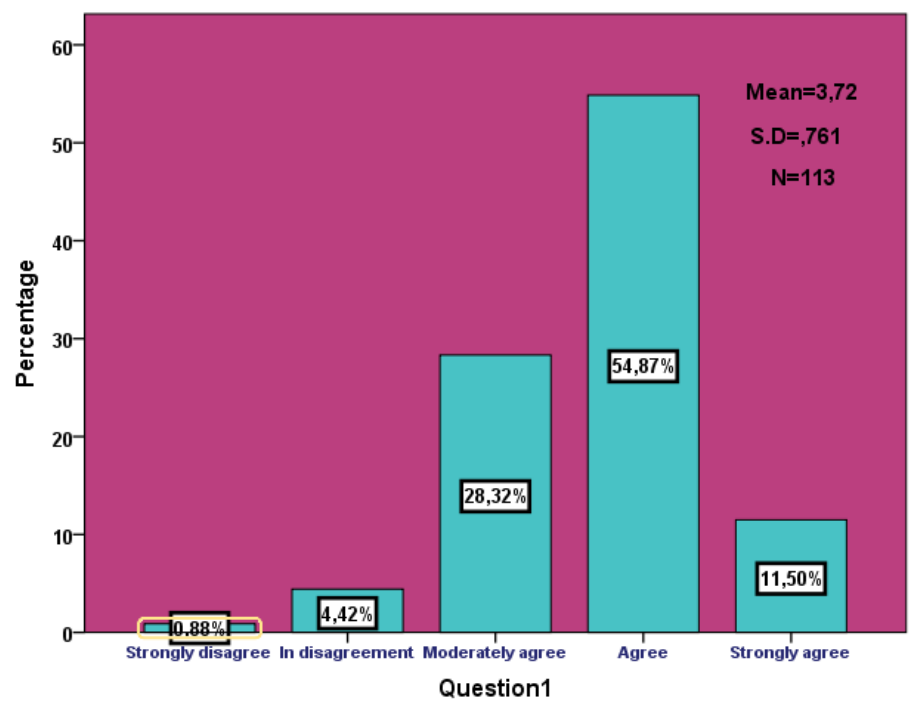

Fig. 8. Analysis of Question 1.

P2: There is an interaction between students and teachers through the zoom or others to carry out group work The interaction between teachers and students through group work such as the Zoom videoconference with its group work option has an average of 3,88 and S.D of ,746 (see Fig. 9). It is also observed that $56,64 \%$ agree

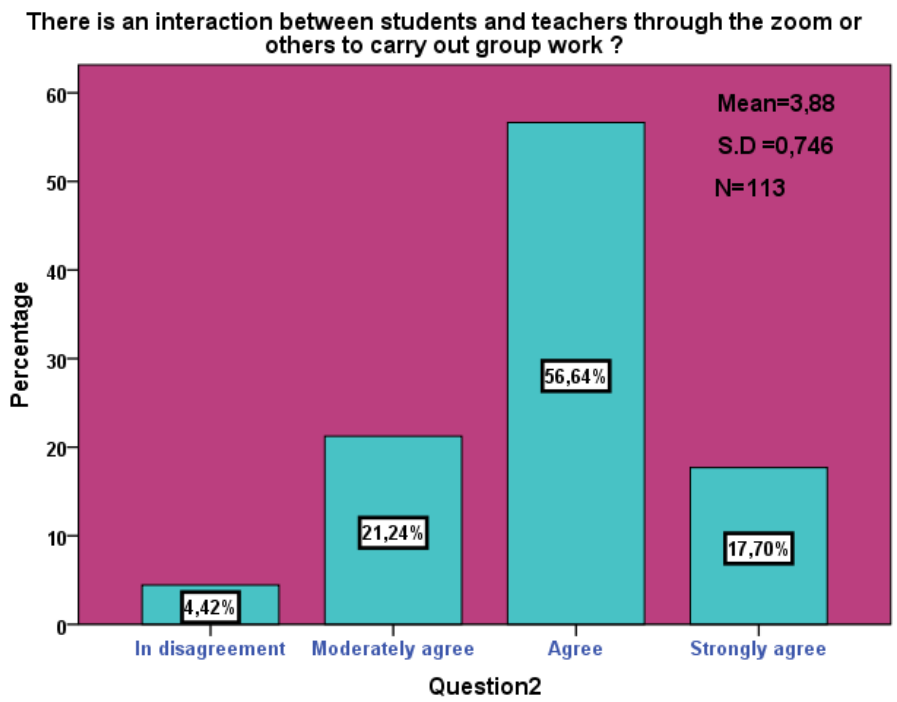

Fig. 9. Analysis of Question 2.

P3: Teachers get students to participate in class through discussions and problems related to the subject

It is observed in Fig. 10, that a 54,87\% it agrees. Although it is true, there is some acceptance from the students, but not in its entirety, since there is $26,55 \%$ who moderately agree; In other words, there are teachers who still carry out their classes in a traditional way. This question has a mean of 3,70 and S.D ,789.

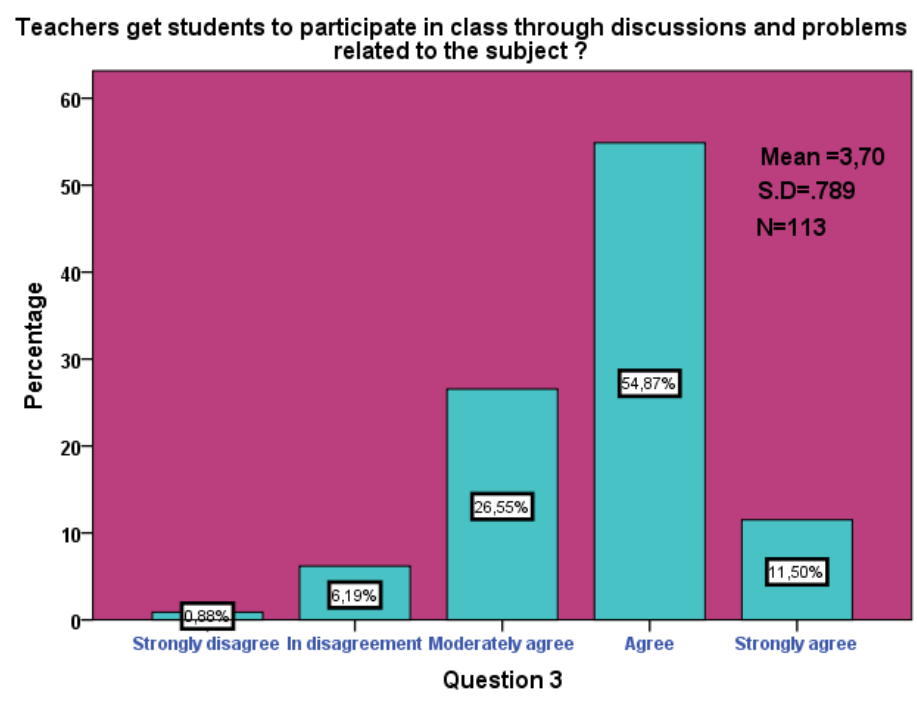

Fig. 10. Analysis of Question 3.

P4: Teachers use the didactic resources in their class session (games, videos, visual organizers and others)

There is a 44,25\% who agree that teachers use didactic resources in the class session. Of the 8 questions, it is the lowest in percentages that agree. It has a mean of 3,58 and a standard deviation of ,989 (see Fig. 11). 
Teachers use the didactic resources in their class session (games, videos, visual organizers and others)?

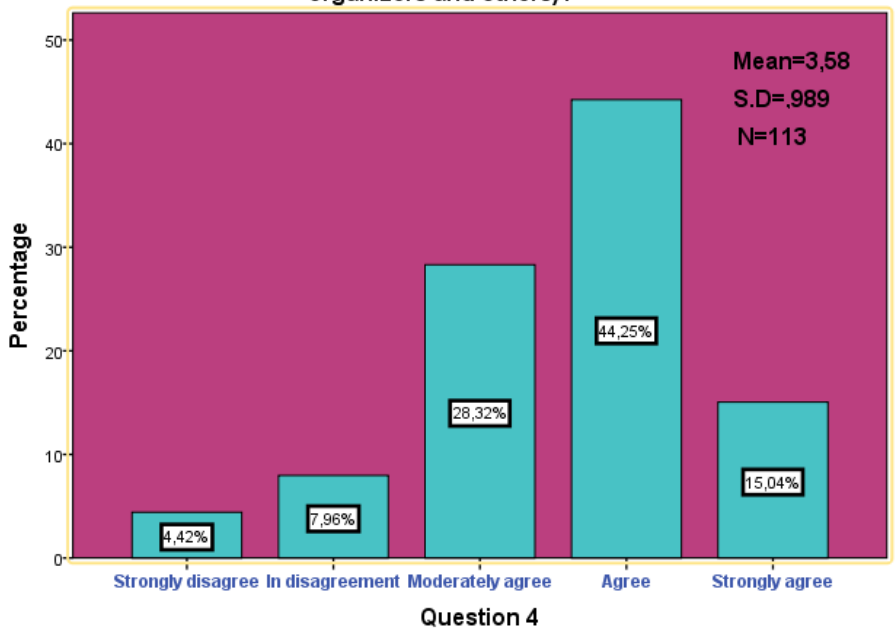

Fig. 11. Analysis of Question 4.

P5: Teachers use digital tools in the development of classes (facebook, canva, whatsapp, youtube or others)

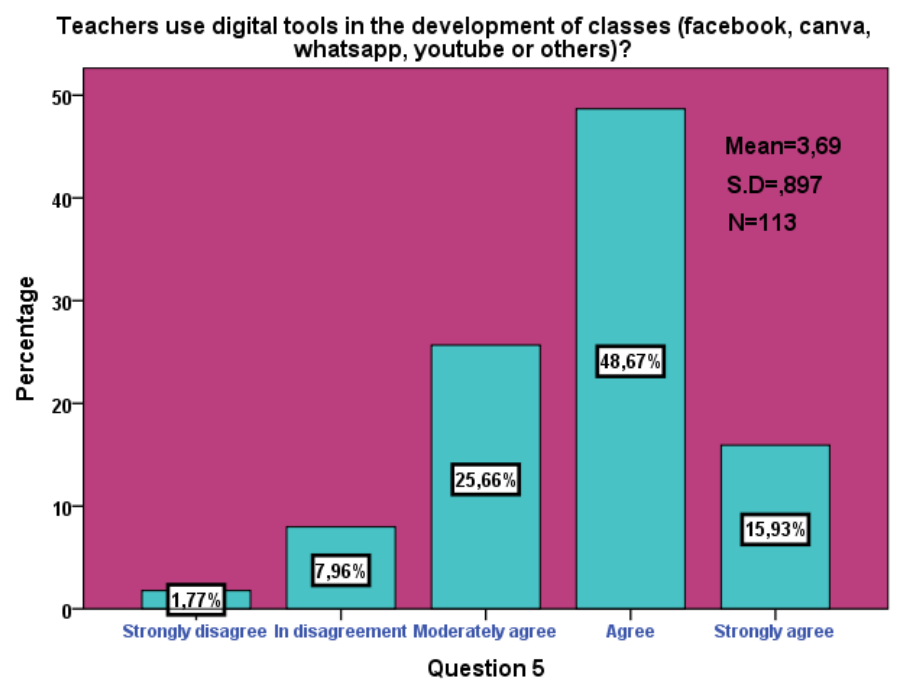

Fig. 12. Analysis of Question 5.

It is seen in Fig. 12. that less than $50 \%$ agree that teachers use digital tools in their class session, with a mean of 3,69 and a standard deviation of, 897. There is a 7,96\% that disagrees.

P6: Teachers use pedagogical resources in the development of their classes (office projector, digital whiteboard, Google drive, Excel, Word, academic Google or others)

The use of pedagogical resources by the teacher in their class session is 48,67\% with a mean of 3,89 and a standard deviation of ,870. There is a percentage of teachers, partially, who use pedagogical tools as a complement in their teaching (see Fig. 13).
Teachers use pedagogical resources in the development of their classes (office projector, digital whiteboard, google drive, Excel, Word, academic google or

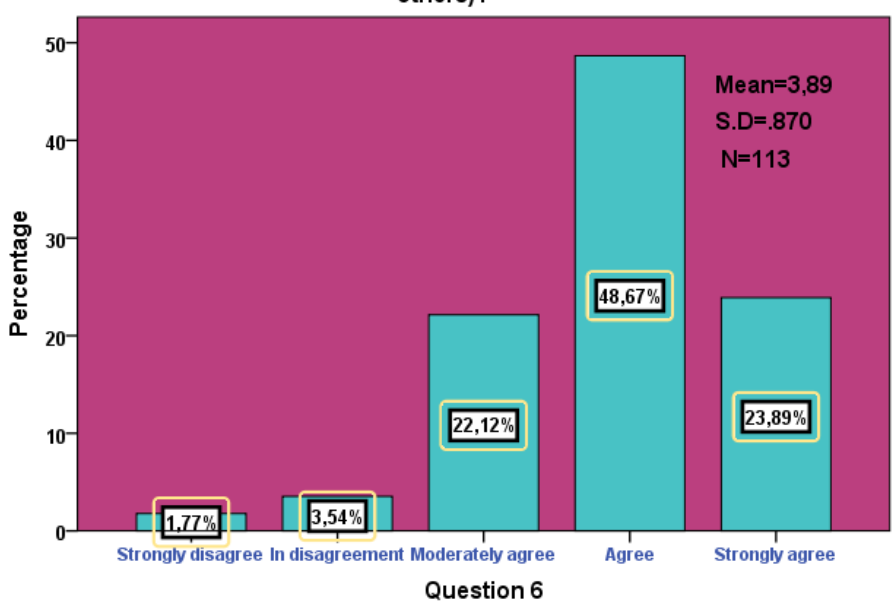

Fig. 13. Analysis of Question 6.

P7: The teacher evaluates the learning at the beginning, development and at the end of the class session (tests, forums, feedback, forms, etc.)

The students state that the teachers agree with $52,21 \%$ in the learning evaluation. However, there is 7,08\% who disagree, since it has a mean of 3,59 and a standard deviation of, 862, (see Fig. 14).

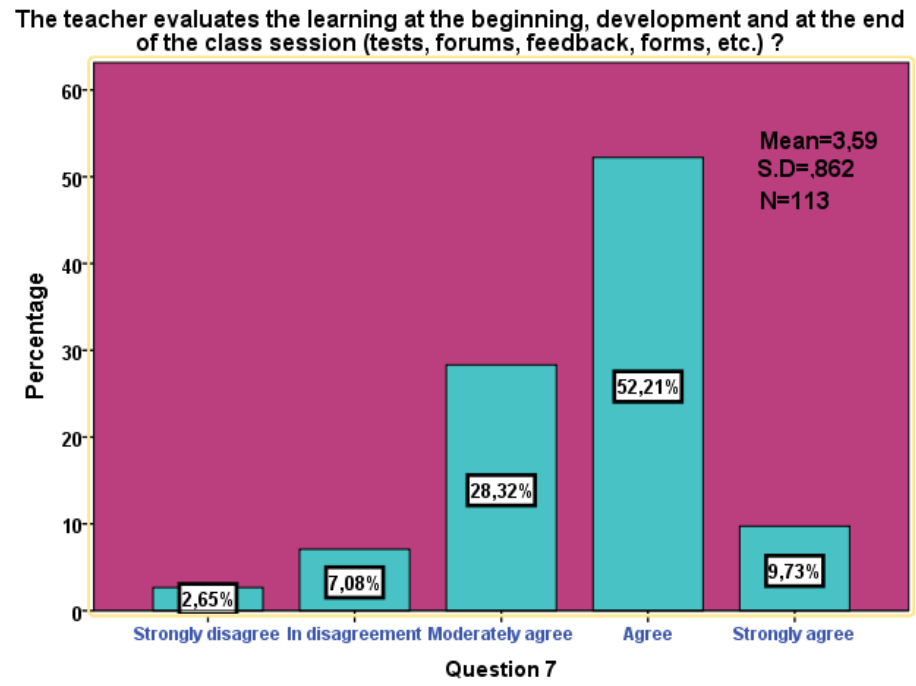

Fig. 14. Analysis of Question 7.

P8: Teachers use the rubric (evaluation criteria) to grade students

In Fig. 15 it is observed that 54,87\% indicate that teachers correctly apply their evaluation system with the use of rubrics and $2,65 \%$ disagree with a mean of 3,93 and S.D, 776 .

3) Box and whisker analysis: The 3 dimensions were analyzed using box and whiskers from Fig. 16 and Table III. The first dimension, which is the teaching strategy, the score of the mean that is represented on the vertical axis and its 


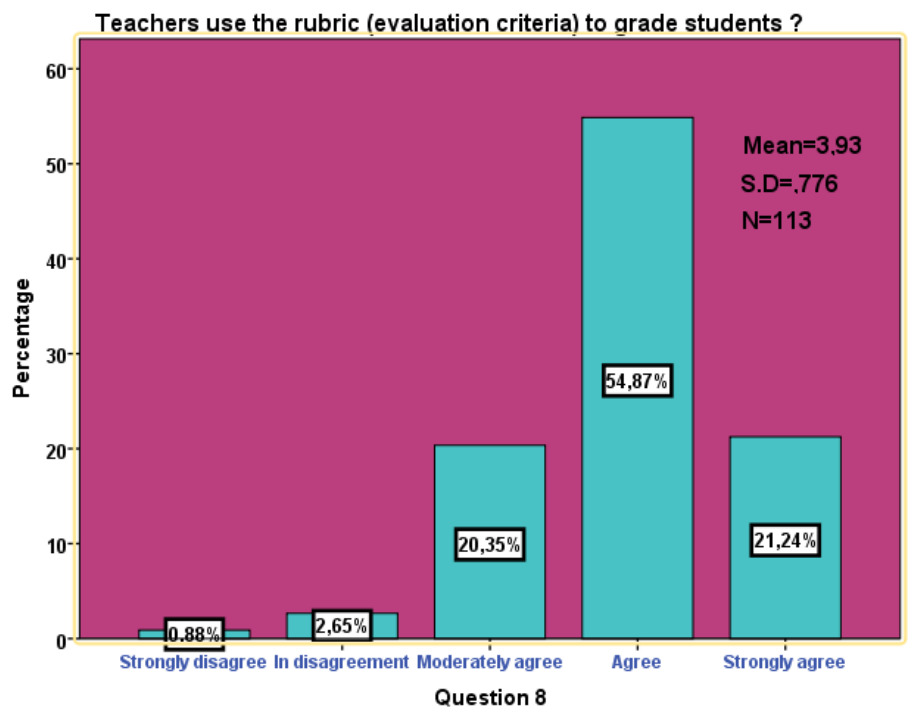

Fig. 15. Analysis of Question 8.

TABle III. Percentile Analysis

\begin{tabular}{|c|c|c|c|c|}
\hline Dimension & $\begin{array}{l}\text { Percentile } \\
25\end{array}$ & $\begin{array}{l}\text { Percentile } \\
50\end{array}$ & $\begin{array}{l}\text { Percentile } \\
75\end{array}$ & $\begin{array}{l}\text { Percentile } \\
95\end{array}$ \\
\hline D1:Teaching strategy & 3,33 & 4 & 4 & 4,66 \\
\hline $\begin{array}{l}\text { D2:Educational resources } \\
\text { and materials }\end{array}$ & 3,33 & 4 & 4,33 & 5 \\
\hline D3:Evaluation & 3,25 & 4 & 4 & 5 \\
\hline
\end{tabular}

median is 4 , which represents quartile 2 of the 50 th percentile of 4 , which coincides with quartile 3 of 75 with a value of 4 ; but it is observed in the whiskers that there is a symmetry; Furthermore, extreme values are observed in the upper part, where a mean score of 5 was obtained for 4 cases, and in the lower part, a mean score of less than 2 was obtained, which was only one case. In dimension 2 , pedagogical resources and materials, the median is also 4; but it is asymmetrical, since one mustache is shorter than the other; Furthermore, it is observed in the box that the highest concentration of the mean score is found between quartile 2 of the 50th percentile with a value of 4 and quartile 3 of the 75th percentile, taking the value of 4.33 , since it is denser; In addition, 2 cases are observed in the lower part that are extreme points to evaluate with a mean score lower than 2 . The evaluation dimension represents a symmetry in the distribution of the mean score, this is validated by the size of the mustache, its median is 4 coinciding with quartile 2 of percentile 50 of value 4 and quartile 3 of percentile 75 taking the value of 4 . It also has extreme values both in the upper and lower part that requires further evaluation. In the upper part it has 4 cases with a mean score 5 and in the lower part it has 4 cases with a mean score of 2 and 2 cases with a mean score slightly higher than 2 .

4) Confidence interval analysis (CI): It is shown in Fig. 17 and Table IV, the comparison of the mean D (mean dimension) with the average of the scores with the 95\% Confidence Interval (95\% CI) that is located in the vertical. A dispersion is observed in all dimensions; having a lower lower limit in

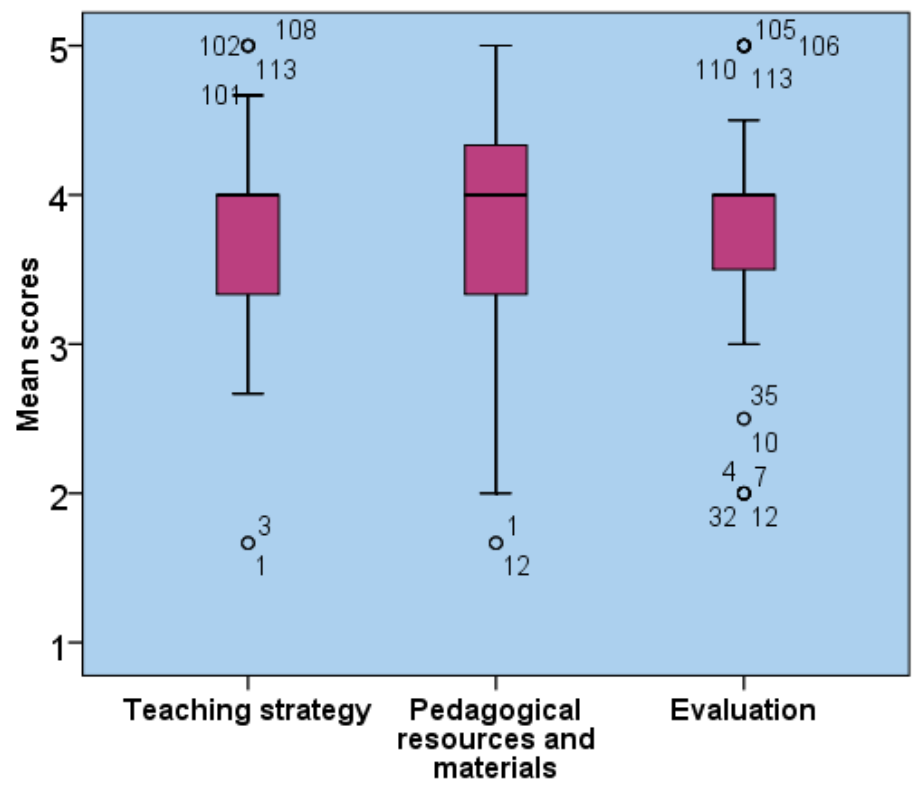

Fig. 16. Boxes and Whiskers.

the mean $\mathrm{D} 2$ dimension (resources and pedagogical materials) with 36,85 and an upper limit in the mean dimension 3 (evaluation) with 3,89 . Likewise, it is observed that the mean total dimension has a lower interval 3,62 and an upper limit $3,86 \%$, where dimension 1 is close to it, which is the teaching strategy.

TABLE IV. CONFIDENCE INTERVAL FOR THE MEAN AT $95 \%(95 \%$ CI)

\begin{tabular}{llllll}
\hline Dimension & $\begin{array}{l}\text { Lower } \\
\text { limit } \\
\% \text { CI })\end{array}$ & $\begin{array}{l}\text { Upper } \\
\text { \% CI) }\end{array}$ & Median & Mean & S.D \\
\hline \hline D1 mean:Teaching strategy & 3,64 & 3,88 & 4 & 3,76 &, 63 \\
\hline $\begin{array}{l}\text { D2 mean:Resources and } \\
\text { pedagogical materials }\end{array}$ & 3,58 & 3,85 & 4 & 3,72 &, 74 \\
\hline D3 mean:Evaluation & 3,62 & 3,89 & 4 & 3,76 &, 72 \\
\hline $\begin{array}{l}\text { D total mean:Mean total } \\
\text { dimension }\end{array}$ & 3,62 & 3,86 & 4 & 3,74 &, 63 \\
\hline
\end{tabular}

\section{DISCUSSION}

The analysis of the focus group and the student surveys have allowed us to triangulate, cross and compare the student's perception qualitatively with the quantitative part about teaching at the university.

The distance learning strategy has not allowed direct human interaction between teachers and students, since face-to-face teaching is different from distance learning [8]. Distance learning, carried out at the university under study, is under development, as it is focusing on training its teachers in the proper use of digital tools. However, training alone does not guarantee an education according to the pedagogical model of the university. In other words, pedagogical guidelines are required in distance learning. Likewise, the trainings oriented to the methodology of the distance modality would help to strengthen teaching. The author [9], states that training in 


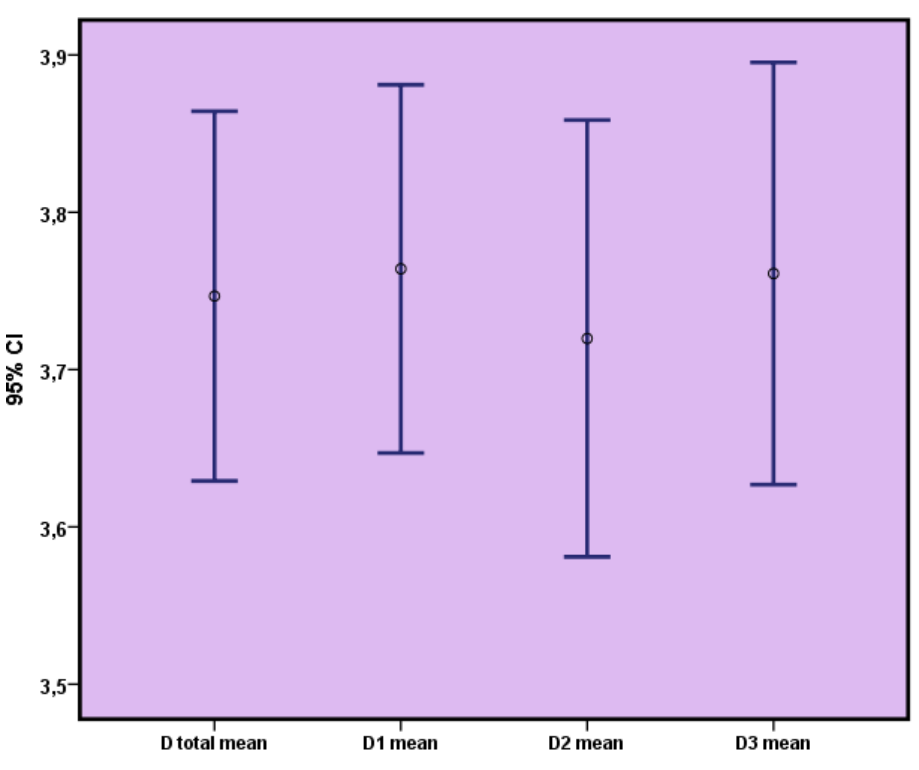

Fig. 17. Confidence Interval Analysis.

digital tools and educational platforms should be developed. However, in our study, information was obtained that teachers should be trained not only in the use of digital tools but also in distance learning strategies. Regarding the uses of resources and pedagogical materials, students partially agree that teachers use them appropriately; However, there are other aspects that prevent the development of distance classes, such as connectivity problems and limited access to the Internet, and to this is added the fact that the majority of students use mobiles that have limited connectivity. El autor [11], agree in their results regarding that teachers should be trained in digital tools to promote student learning. On the other hand, in the dimension of the evaluation of the learning of the students, the teachers presented limitations to evaluate in the distance modality; but this was partially overcome with training and the use of virtual classroom tools. In summary, the students stated that distance education is partially accepted, since the interaction between those involved is minimal, coinciding with the author [12] in their conclusions, regarding the fact that face-to-face teaching has a greater impact on the interaction between student and teacher.

\section{CONCLUSiOn AND Future Work}

After carrying out the qualitative and quantitative analysis, we conclude that teachers must further strengthen the strategies for teaching their classes, as well as the way to carry out evaluations in the distance mode and make the appropriate use of resources and educational materials. The pedagogical aspect is different between face-to-face teaching and distance learning, so the latter aspect should be strengthened. It is recommended to develop constant training not only in the use of digital tools but also in the didactics of teaching strategies. The connectivity problem and the internet have been limitations in the teaching process and in the evaluation system, since the majority of students used mobile computers and some did not have cameras for evaluation. There was a difficulty in the teamwork among the students to be able to carry out their assignments, forums and group works of exposition. We suggest as future work to carry out a comparative analysis of distance, face-to-face and blended classes involving university teachers and authorities. In addition, we also suggest to carry out a study about the digital gap that exists among the students, since internet connectivity problems emerged.

\section{ACKNOWLEDGMENT}

This work was sponsored by the University of Sciences and Humanities and the research direction. To acknowledge Dr. Carlos Sotomayor Beltrán for the suggestions in the article.

\section{REFERENCES}

[1] W. Ali, "Online and remote learning in higher education institutes: A necessity in light of covid-19 pandemic." Higher education studies, vol. 10, no. 3, pp. 16-25, 2020.

[2] C. Sotomayor-Beltran and L. Andrade-Arenas, "A spatial assessment on internet access in peru between 2007 and 2016 and its implications in education and innovation," in 2019 IEEE 1st Sustainable Cities Latin America Conference (SCLA), 2019, pp. 1-4.

[3] B. Williamson, R. Eynon, and J. Potter, "Pandemic politics, pedagogies and practices: digital technologies and distance education during the coronavirus emergency," Learning, Media and Technology, vol. 45, no. 2, pp. 107114, 2020.

[4] L. Li, Y. Chen, Z. Li, D. Li, F. Li, and H. Huang, "Online virtual experiment teaching platform for database technology and application," in 2018 13th International Conference on Computer Science Education (ICCSE), 2018, pp. 1-5.

[5] N. Asadi, F. Khodabandeh, and R. R. Yekta, "Comparing and contrasting the interactional performance of teachers and students in traditional and virtual classrooms of advanced writing course in distance education university," Turkish Online Journal of Distance Education, vol. 20, no. 4, pp. 135-148, 2019.

[6] J. G. Coello, J. T. Salazar, and M. L. N. Taborda, "Peruvian students in pandemic: Digital gap and what is done from engineering programs?" in 2020 IEEE International Symposium on Accreditation of Engineering and Computing Education (ICACIT), 2020, pp. 1-4.

[7] K. Kedraka and C. Kaltsidis, "Effects of the Covid-19 pandemic on university pedagogy: students' experiences and considerations," European Journal of Education Studies, vol. 7, no. 8, 2020.

[8] S. Elmendili and S. Saaidi, "The Distance learning practices in Moroccan universities in the coronavirus era," The Journal of Quality in Education, vol. 10, no. 16, 2020.

[9] O. Yarmak, T. Shkaiderova, E. Strashko, M. Bolshakova, and L. Garas, "Institution of higher education transformation and society's response to distance learning during the covid 19 pandemic," vol. 244, 2021.

[10] S. T. Calvo, L. Cervi, F. Tusa, and A. Parola, "Educación en tiempos de pandemia: reflexiones de alumnos y profesores sobre la enseñanza virtual universitaria en españa, italia y ecuador," Revista Latina de Comunicación Social, no. 78, pp. 1-21, 2020.

[11] S. Deb Roy, "Application of ICTs in Teaching-Learning Process," International Research Journal of Interdisciplinary \& Multidisciplinary Studies (IRJIMS) A Peer- 
Reviewed Monthly Research Journal, vol. 1, no. VII, 2015.

[12] S. Bali and M. Liu, "Students' perceptions toward online learning and face-to-face learning courses," in Journal of Physics: Conference Series, vol. 1108, no. 1. IOP Publishing, 2018, p. 012094.

[13] S. P. Gonçalves, M. J. Sousa, and F. S. Pereira, "Distance learning perceptions from higher education students - the case of portugal," Education Sciences, vol. 10, no. 12, p. 374, 2020.

[14] N. Bergdahl and J. Nouri, "Covid-19 and Crisis-Promted Distance Education in Sweden," Technology, Knowledge and Learning, 2020.

[15] L. Andrade-Arenas, D. L. Nunez, and C. SotomayorBeltran, "Leveraging digital tools for a better virtual teaching-learning process in a private university of lima," in EDUNINE 2021 - 5th IEEE World Engineering Education Conference: The Future of Engineering Education: Current Challenges and Opportunities, Proceedings, 2021. [Online]. Available: www.scopus.com

[16] A. D. Rio-Chillcce, L. Jara-Monge, and L. AndradeArenas, "Analysis of the use of videoconferencing in the learning process during the pandemic at a university in lima," International Journal of Advanced Computer Science and Applications, vol. 12, no. 5, 2021. [Online]. Available:
http://dx.doi.org/10.14569/IJACSA.2021.01205102

[17] Q. Kharma, K. Nairoukh, A. Hussein, M. Abualhaj, and Q. Shambour, "Online learning acceptance model during covid-19: An integrated conceptual model," International Journal of Advanced Computer Science and Applications, vol. 12, no. 5, 2021. [Online]. Available: http://dx.doi.org/10.14569/IJACSA.2021.0120561

[18] G. Georgieva-Tsaneva and I. Serbezova, "Online training and serious games in clinical training in nursing and midwife education," International Journal of Advanced Computer Science and Applications, vol. 12, no. 5, 2021. [Online]. Available: http://dx.doi.org/10.14569/IJACSA.2021.0120539

[19] H. H. Razami and R. Ibrahim, "Distance education during covid-19 pandemic: The perceptions and preference of university students in malaysia towards online learning," International Journal of Advanced Computer Science and Applications, vol. 12, no. 4, 2021. [Online]. Available: http://dx.doi.org/10.14569/IJACSA.2021.0120416

[20] C. Rodriguez-Sabiote, J. Alvarez-Rodríguez, and R. D. P. Gámez-Durán, "Methodological limitations and feasible solutions in the assessment and grade calculation obtained through the rubrics as skills assessment strategies of higher education students and other levels," Meta: Avaliacao, vol. 10, no. 30, pp. 621-637, 2018. [Online]. Available: www.scopus.com 